\title{
Why research?
}

\author{
Stephen Hancocks OBE \\ Editor-in-Chief
}

The BDJ Upfront section includes editorials, letters, news, book reviews and interviews. Please direct your correspondence to the News Editor,

Adrian O’Dowd at BDJNews@nature.com. Press releases or articles may be edited, and should include a colour photograph if possible.

$\mathrm{T}$ he end of last month saw ExCeL London Convention Centre host the International Association of Dental Research's (IADR) General Session. Attracting thousands of dental researchers from around the world, the meeting was the first to be held in the UK for many years and provided an excellent opportunity for this country to present its best research as well as welcome that of others from many nations.

The UK is currently well represented at IADR in the persons of the president, Professor Angus Walls (Edinburgh) and the vice president Paula Moynihan (Newcastle) and the $B D J$ portfolio also took the opportunity to be very visible at the conference. Holding editorial board meetings for three of our publications, the $B D J, B D J$ Open (the inaugural meeting) and Evidence Based Dentistry, we also had a booth and sponsored a symposium. This latter was entitled Altmetrics - the new Impact Factor? and was co-hosted with the British Dental Editors and Writers Forum.

Impact Factors (IFs) have been much debated over the years and have attracted a good deal of criticism as being a biased and not entirely reliable measure of the value of a publication. Despite this, IFs have been used by libraries, academic institutes, funders and many others as the basis for decision-making on the allocation of jobs, grants and resources.

Although almost universally agreed to be a less than perfect index, it was acknowledged to be the only one, that is until the digital age and the arrival of altmetrics. These are metrics which are derived from internet sources on which research content is reproduced or shared and includes social media, print and broadcast media as well as policy documents, blogs and so forth. A company called Almetric brings these references together to form a roundel or 'doughnut' (American; Donut!) composed of weightings from the differing sources, to create an 'Altmetric score' indicating the extent of exposure of that content.
We wanted to raise the issue since, for the first time, Almetrics provides a realistic, understandable and real-time alternative to the traditional IF measure and it is one that we at the $B D J$ believe has exciting potential for the future. This was highlighted particularly at the symposium by the question posed by one of the four speakers, Professor Liz Kay of Peninsula Dental School. 'Why', she asked of the audience, pointedly and as only she can with an element of cheeky provocation 'do you do research?' Though temporarily silenced as such gatherings often are when challenged, two answers emerged, 'because we are curious' and 'because we want to share what we find'. It is the second of these that helped focus our attention on what has to be the main purpose of publication, namely effective dissemination was one of its intended purposes. What emerged was the concern that quantity was not necessarily quality; that a piece of research that resulted in thousands of tweets did not necessarily make it more worthy. However, what it does do is to give it more exposure and the counter argument is that the greater the awareness the higher the likelihood that someone somewhere can add to, enhance or apply the knowledge to the betterment of us all. I also argue that in terms of opinion as well as accuracy this opens up research papers to the whole world as potential peer reviewers meaning that the traditional reliance on one or two experts is also significantly broadened with the ultimate of transparencies.

As regular readers may have noted the $B D J$ does very well in terms of Altmetric scores for

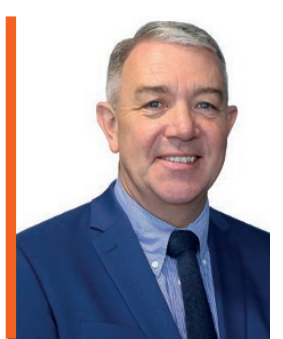

\section{'Why do you do research? Because you want to share what you find...'}

of the subject matter and results.

Indeed, behind the push for open access publication is precisely the notion that if the results of research are of benefit to humankind then they should not be shuttered away in academic journals ring-fenced by libraries, institutions and subscriptions but made as widely available as possible. What better forum than the world wide web not only to broadcast findings but to provide the opportunity for people in other walks of life to make connections, bounce ideas and possibly advance our knowledge in hitherto unthought of ways?

Like any new kid on the block, altmetrics has its doubters and detractors. The symposium provided the opportunity for some of these concerns to be raised, which its published content making us the highest rated dental publication in the world by these measures. Apart from being very pleasing of itself, this accolade is more important because it means we are reaching more readers and gaining greater exposure for our authors and for their work. This objective evidence is reinforced by anecdotal information from authors who report that having papers published in the $B D J$ brings a swift and somewhat surprising flood of emails, contacts and comments not experienced when publishing elsewhere.

Our thanks are due to all those involved in the symposium but mostly to the authors who publish with us, for whom we can help answer the question, why research?

DOI: 10.1038/sj.bdj.2018.651 